\title{
Ground and surface water quality assessment of Palladam Taluk using Geographical Information System and Modified National Sanitation Foundation -Water Quality Index
}

\section{R. Chitradevi}

Research and Development Center, Bharathiar University, Coimbatore (Tamil Nadu), India \& Department of Chemistry, Sri GVG Visalakshi College for Women, Udumalpet - 642128 (Tamil Nadu), India

\section{P. N. Magudeswaran*}

Hindustan College of Engineering and Technology, Coimbatore - 641050 (Tamil Nadu), India

Vikas D. Ghadamode

National Geophysical Research Institute, Hyderabad -500007 (Telangana), India

K. Poonkodi

Post-Graduate Department of Chemistry, Nallamuthu Gounder Mahalingam College, Pollachi - 642001 (Tamil Nadu), India

\section{Anitha}

Department of Chemistry, Sri GVG Visalakshi College for Women, Udumalpet - 642128 (Tamil Nadu), India

${ }^{*}$ Corresponding author. Email: magudeswaran2021@gmail.com

\section{How to Cite}

Chitradevi , R. et al. (2021). Ground and surface water quality assessment of Palladam Taluk using Geographical Information System and Modified National Sanitation Foundation -Water Quality Index. Journal of Applied and Natural Science, 13(3), 954 - 961. https://doi.org/10.31018/jans.v13i3.2752

\begin{abstract}
In this work, the assessment of surface and ground water quality of Palladam Taluk, Tiruppur, district, Tamil Nadu, India were carried out using Geographical Information System (GIS) and Modified National Sanitation Foundation -Water Quality Index (MNSFWQI). Four samples from surface and twenty seven samples from ground water sources were taken from Palladam Taluk, Tiruppur District. In the current study, the surface and ground water samples were analysed for temperature, $\mathrm{pH}$, dissolved oxygen (DO), electrical conductivity (EC), biological oxygen demand (BOD), turbidity, total dissolved solids (TDS), total hardness (TH), faecal coliforms (FC), total phosphate (TP), total nitrate (TN), chlorides $(\mathrm{Cr})$, sodium $\left(\mathrm{Na}^{+}\right)$and fluoride $\left(\mathrm{F}^{-}\right)$ions to investigate the suitability of surface and ground water for drinking and agricultural purposes through Geographic information system (GIS) and modified rational sanitation foundation water quality index (MNSF-WQI) technique. The concentrations of $\mathrm{TH}, \mathrm{TDS}^{-\mathrm{Cl}^{-}}$and $\mathrm{Na}^{+}$were observed to be above the desirable limit of World Health Organization (WHO) guidelines and Bureau of Indian Standards (BIS). whereas F, BOD, DO, EC, TP, TN, FC and temperature were within the acceptable limits. The GIS-based WQI map analysis indicated that $45 \%$ of the study area having good water quality index and the remaining area showed medium quality water. Dyeing and textile industries in the study area are responsible for deteriorating the quality to medium quality of water which was not appropriate for direct utilization and needed prior treatment. There is no detailed report on assessment of the surface and ground water qualty of Palladam Taluk in Tamil Nadu using GIS and MNSF-WQI techniques.
\end{abstract}

Keywords: GIS, MNSF-WQI, Palladam Taluk, Physico-chemical parameters, Water Quality

\section{INTRODUCTION}

Over the last few decades, there has been an increasing need to conserve natural resources, particularly water which is the most important substance and is used equally by all realms of life (Mohammad and Saminu, 2012). Our environmental systems have been severely impacted by human activities, degrading water quality and water availability. Potable water comes from surface and groundwater, which is free from contaminants and microbes. Most of the diseases are directly related to poor drinking water quality and unhygienic conditions (World Health Organization, 2017). Inadequate control of hazardous effluents and disposal 
methods from the industries leads to the contamination of surface as well groundwater. Nowadays, the availability of good quality water has become a point of interrogation. There is an increasing concern about the availability and quality of water worldwide, and it is estimated that the demand for water will increase by 20 $30 \%$ by 2050 (Wada et al., 2016). In Tamil Nadu, water demand is growing rapidly due to population growth and also due to higher per capita needs triggered by economic growth. There are 17 major river basins in Tamil Nadu, where Kaveri is the only largest river basin and Amaravati River is the longest tributary of the Kaveri River. The Amaravati River is the primary source of water for an irrigation, domestic water supply and industrial use in the districts of Karur and Tirupur. The rapid growth in population, the progress of industrialization, agrochemicals, and the dumping of urban and industrial waste have all played a key role in groundwater pollution and increased enormously the pressure on water resources (Chandra et al., 2015). Once the water is contaminated, its quality cannot be reestablished by preventing the pollutants from the source, and hence, it becomes very crucial to monitor the quality of groundwater frequently and to plan methods and means to safeguard it (Ramakrishnaiah et al., 2009). There are a number of water quality assessment methods, including a single factor, multi-index, fuzzy mathematics, grey system evaluation, artificial neural network, multicriteria analysis, geographical interpolation and multivariate statistical approach (Dixon and Chiswell, 1996; Wang et al., 2016; Ji et al., 2016; Deng and Wang, 2017; Mladenović et al., 2018; Rakotondrabe et al., 2018; Chen et al., 2019).

The Water Quality Index (WQI) is one of the most effective tool for monitoring surface and groundwater pollution. The WQI provides a unique number which expresses the overall quality according to the various parameters. It summarizes large amounts of water quality data into simple terms, i.e., excellent, good, medium, bad etc (Pius and Jerome, 2011). The emergence of geospatial technologies such as the use of the Geographic Information System (GIS) enables rapid and cost-effective study and management of natural resources. Consequently, this technique has extensive applications, including the spatial distribution of groundwater quality parameters (Ganesh Babu and Sashikkumar, 2013; Ramakrishna et al., 2013). Therefore, many researchers (Vasanthavigar et al., 2010; Saleem et al., 2016; Boateng et al., 2016; Tiwari et al., 2018; Rawat and Singh, 2018) have successfully used this technique in groundwater studies, both for exploration and for quality mapping.

The aim of the present study was to investigate the ground and surface water quality of Palladam Taluk with the following objectives: i) to analyze physicochemical parameters of the study area ii) to calculate
NSF-WQI using nine water quality parameters, iii) to explore the water quality parameters by GIS technique, iv) to compare MNSF-WQI and NSF-WQI v) to determine the level of pollution and vi) to evaluate the safety of water for domestic purpose by comparing the results with the standards prescribed by World Health Organization (WHO).

\section{MATERIALS AND METHODS}

\section{Study area}

The sampling points chosen for the study were from the urban and rural area of Palladam Taluk, Tiruppur District. The latitude and its longitude of Palladam Taluk are $0.9909^{\circ} \mathrm{N}, 77.2858^{\circ} \mathrm{E}$ respectively. The total study area of the Sampling station was 7.32 Square feet were calculated using Arc GIS 10.8 software and location study area map is shown in Fig. 1.

Thirty-one water samples were collected from different locations at one time during September, October and November month of 2019 and marked for the evaluation of physical and chemical attributes. 22 samples from handpump of depth from $106 \mathrm{~m}$ to $200 \mathrm{~m}, 5$ from open well and 4 (S11, S13, S18 and S21) water samples from open source (lake). The water samples were filtered using a $4.5 \mu \mathrm{m}$ Whatman filter paper to separate any suspended matter present. Total hardness, sodium, chloride, fluoride, electrical conductivity, turbidity, dissolved oxygen and biological oxygen demand were performed in the laboratory by American Public Health Association (APHA, 2017). Calcium (Ca), magnesium (Mg), and total hardness were evaluated by titrimetry (Deshmuk and Sainath, 2016), sodium (Na) was detected by Flame photometer (Elico -130). Electrical conductivity (EC) and turbidity was measured with the help of Conductivity meter (Elico-CM 180) and Turbidity meter (Elico-CL 52D), respectively. Dissolved oxygen (DO), biological oxygen demand (BOD) was carried out using Winkler's method. The concentration of fluoride and phosphate ions were analysed by UVVis Spectrophotometer (Shimadzu Model: UV-1800).

All the experiments for each sample were repeated thrice to attain quality assurance and control the quality. All the water quality parameters are expressed in $\mathrm{mg} / \mathrm{L}$ except $\mathrm{pH}$ and turbidity. Each parameter was compared with the standards prescribed by WHO (2017) for drinking and public health purposes.

\section{Water quality index (WQI)}

WQI was used to evaluate the combined effect of individual water quality parameter on the overall quality of water (Mitra et al., 2006). NSF-WQI (Cristable et al., 2020; Zotou et al., 2020) was computed by using qi and Wi as shown below (eq (1))

$\mathrm{WQI}=\sum_{i=1}^{n} W_{i} q_{i}$ 


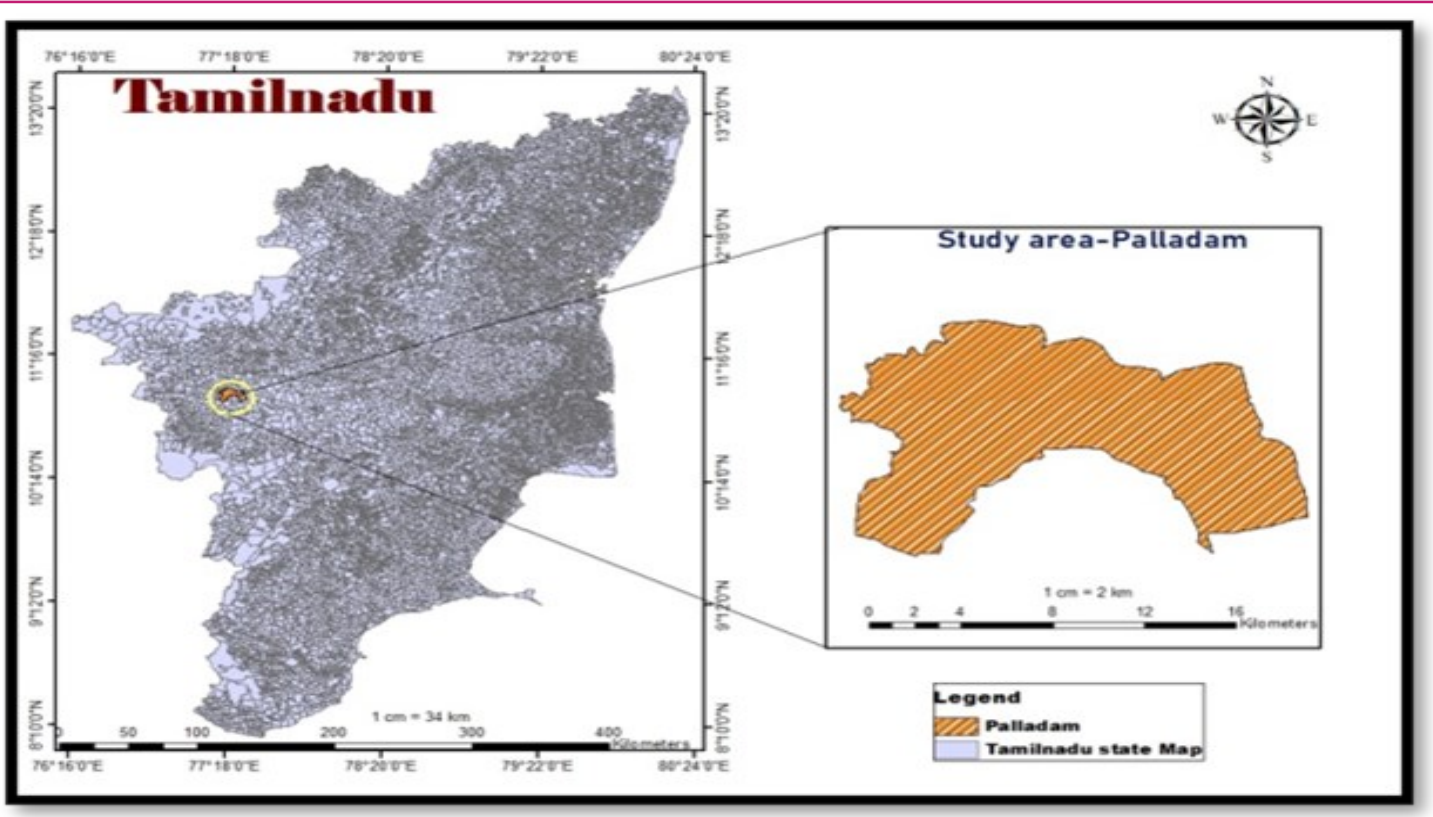

Fig. 1. Study area map- Palladam Taluk.

$\mathrm{NSF}-\mathrm{WQI}=(0.17 \mathrm{DO}+0.16 \mathrm{FC}+0.11 \mathrm{pH}+0.11 \mathrm{BOD}+$ $0.10 \mathrm{Tem}+0.10 \mathrm{TP}+0.10$ Nitrate $+0.08 T U R+0.07 T D S$ )

The MNSF-Water Quality Index Formula was derived by altering NSF-WQI with seven water quality parameters. BOD must be calculated after incubation for 5 days. Since BOD calculation is a time-consuming process, the modified WQI formula without BOD and phosphate can be used to calculate the MNSF-WQI. For that, the weighing factor of BOD and TP was distributed to other seven parameters i.e Temperature, DO, FC $\mathrm{pH}, \mathrm{TN}$, TUR and TDS by using mathematical principle of proportion and summation.

The resultant formula of MNSF-WQI was, MNSF-WQI $=0.22 \mathrm{DO}+0.20 \mathrm{FC}+0.14 \mathrm{pH}+0.13 \mathrm{Tem}+$ $0.13 \mathrm{TN}+0.10 T U R+0.09 T D S$

\section{Spatial analysis using GIS}

Spatial analysis of various physico-chemical parameters was performed using GIS contouring methods with Arc-GIS 10.8. Inverse-distance-weighted interpolation (IWI) techniques were used to prepare spatial distribution maps for each physicochemical parameter. The spatial distribution map of the $\mathrm{pH}, \mathrm{EC}, \mathrm{TDS}, \mathrm{TH}, \mathrm{Na}^{+}$, $\mathrm{Cl}^{-}, \mathrm{F}^{-}, \mathrm{BOD}, \mathrm{DO}$ and Temperature have been created for Palladam Taluk for ground and surface water quality index. GIS map helps us to understand the current status of ground and surface water in the study area.

\section{RESULTS AND DISCUSSION}

Spatial analysis of water quality parameters $\mathrm{pH}, \mathrm{TH}$, TDS, Cl, F, BOD, EC, DO, temperature and $\mathrm{Na}$ from the 31 water samples of Palladam Taluk are shown in
Figs. 2 to 11 and the results are tabulated in Table 1. $\mathrm{pH}$ refers to the degree of acidity or alkalinity of water, is a crucial indicator that can be used to assess water quality and degree of contamination in water bodies (Ameen et., 2019). $\mathrm{pH}$ of the analysed water samples was found to be in the range from 7.5 to 9 indicating slightly alkaline nature due to the presence of carbonate and bicarbonate ions. Spatial analysis of $\mathrm{pH}$ value of the samples (Fig. 2) indicated that 28 samples were within the desirable limits (6.5-8.5) as per World Health Organization (2017) and Bureau of Indian Standards (2012) guidelines except for three sampling points S9, S15 and S18. TH in the water samples ranged from $153 \mathrm{mg} / \mathrm{L}$ to $2386 \mathrm{mg} / \mathrm{L}$ with an average value of $798 \mathrm{mg} / \mathrm{L}$. The spatial map (Fig. 3) showed that $48.4 \%$ are $>600 \mathrm{mg} / \mathrm{L}$ and $51.6 \%$ were greater than $600 \mathrm{mg} / \mathrm{L}$ as per standard limits recommendation of WHO ( 2017) and BIS (2012). A high concentration of $\mathrm{TH}(2386 \mathrm{mg} / \mathrm{L})$ beyond permissible limit was observed in Palladam Taluk, similar results were obtained (Arumugam and Elangovan, 2016) for Groundwater of Avinashi- Tirupur area (2560 mg/L). The value of TDS in the water samples was ranged from $72 \mathrm{mg} / \mathrm{L}$ to 4440 $\mathrm{mg} / \mathrm{L}$ (average value $1697 \mathrm{mg} / \mathrm{L}$ ). Spatial analysis of TDS concentrations of the water (Fig. 4) revealed that $16.2 \%$ of samples were within the adequate limit (500 $\mathrm{mg} / \mathrm{L}), 25.8 \%$ samples were in acceptable (500-1500 $\mathrm{mg} / \mathrm{L}$ ) limit and $58 \%$ of the samples were above the permissible (>1500 $\mathrm{mg} / \mathrm{L})$ limit as per standard limit of WHO (2017) and BIS ( 2012). A higher TDS value reflects inorganic pollutants in surface and ground water samples (Ewaid et al., 2018). The $\mathrm{Cl}^{-}$ion concentration in the study area was found to be in the range from 60 $\mathrm{mg} / \mathrm{L}$ to $1540 \mathrm{mg} / \mathrm{L}$ and the average value was $637 \mathrm{mg} /$ L. The spatial analysis of $\mathrm{Cl}^{-}$(Fig. 5) showed that 


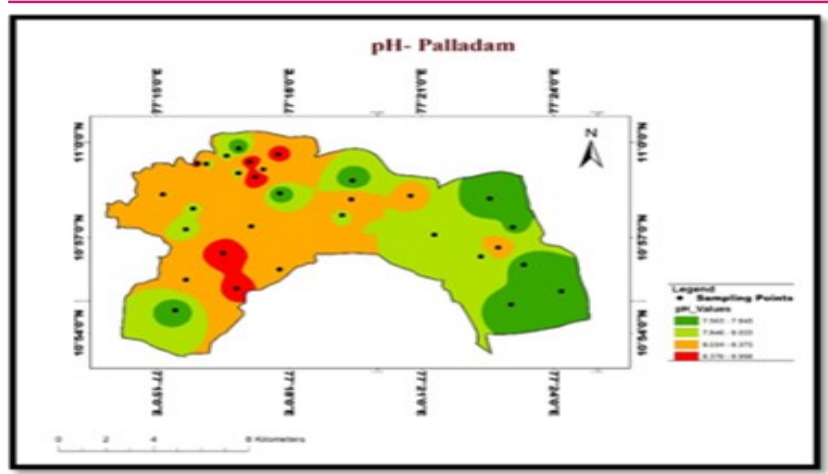

Fig. 2. Spatial distribution of $\mathrm{pH}$.

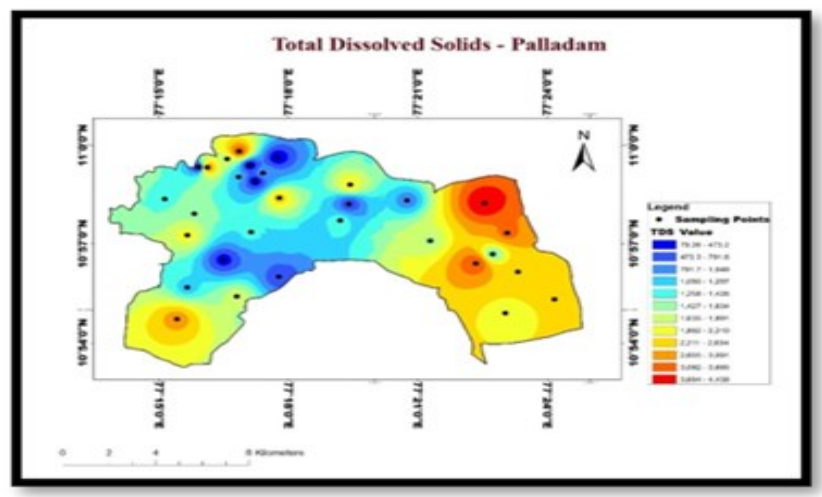

Fig. 4. Spatial distribution of total dissolved solids (TDS).

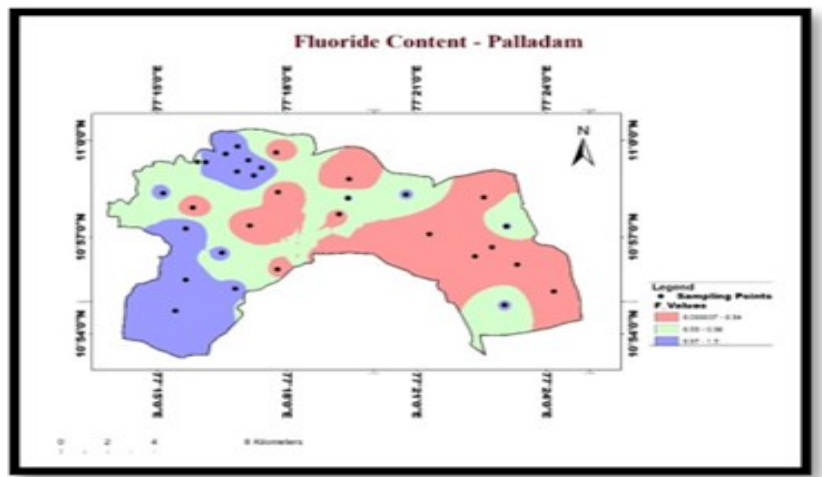

Fig. 6. Spatial distribution of fluoride.

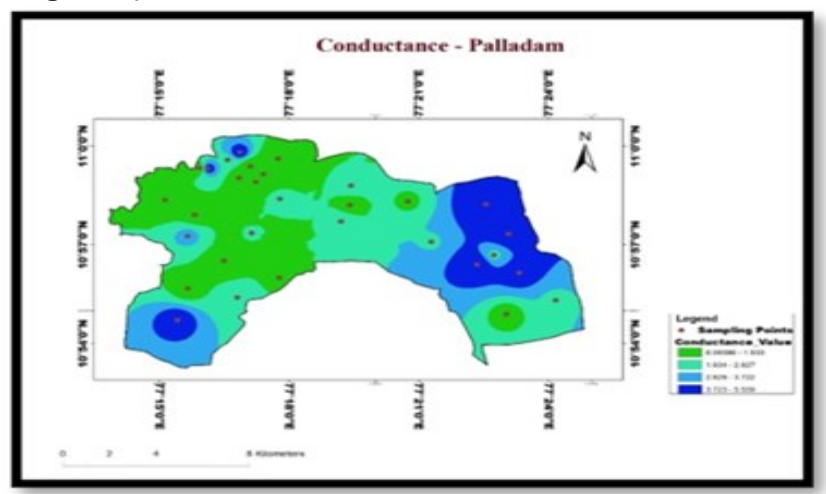

Fig. 8. Spatial distribution of electrical conductivity.

93.5\% of the water sample falls within permissible limit ( $<1000 \mathrm{mg} / \mathrm{L})$ while $6.5 \%$ of the sample were above the permissible limit. Sources of fluoride are geogenic to groundwater, but an important contribution comes from industrial effluents. (Yadav et al., 2015). F ion concen-

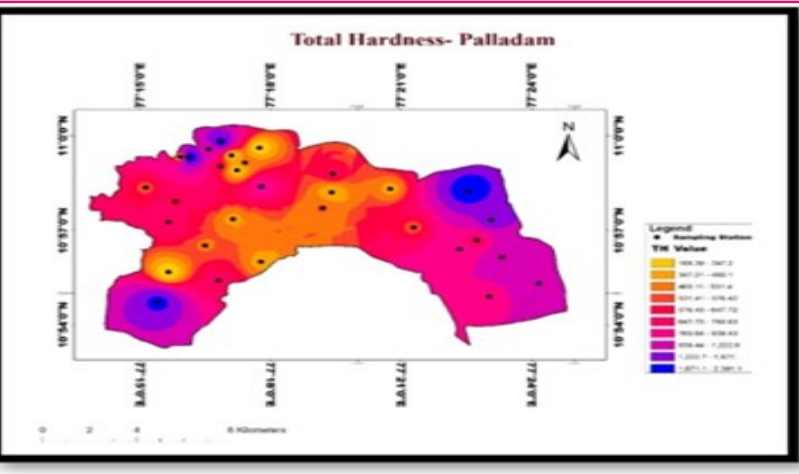

Fig. 3. Spatial distribution of Total Hardness.

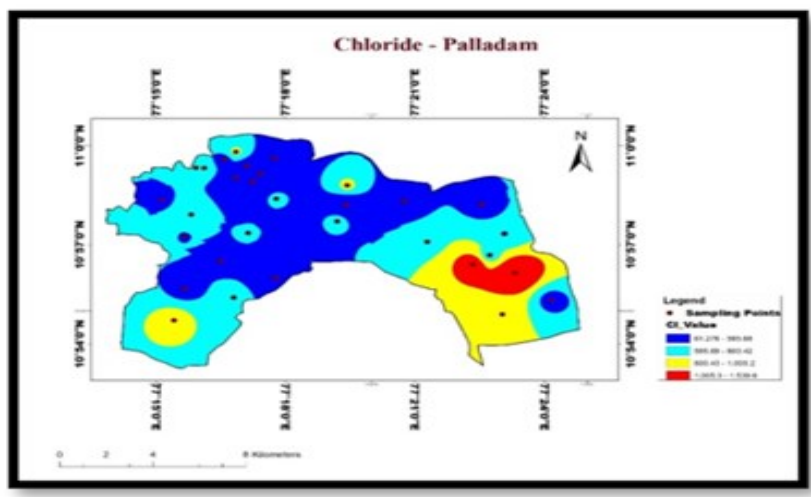

Fig. 5. Spatial distribution of chloride.

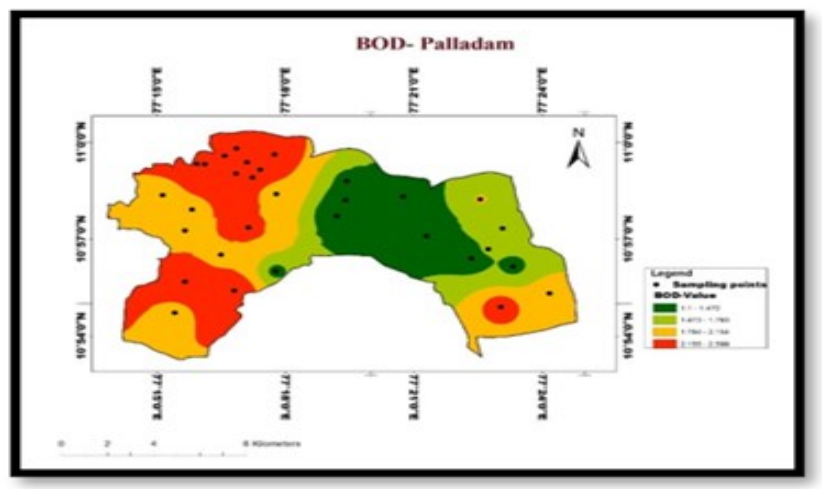

Fig. 7. Spatial distribution of $B O D$.

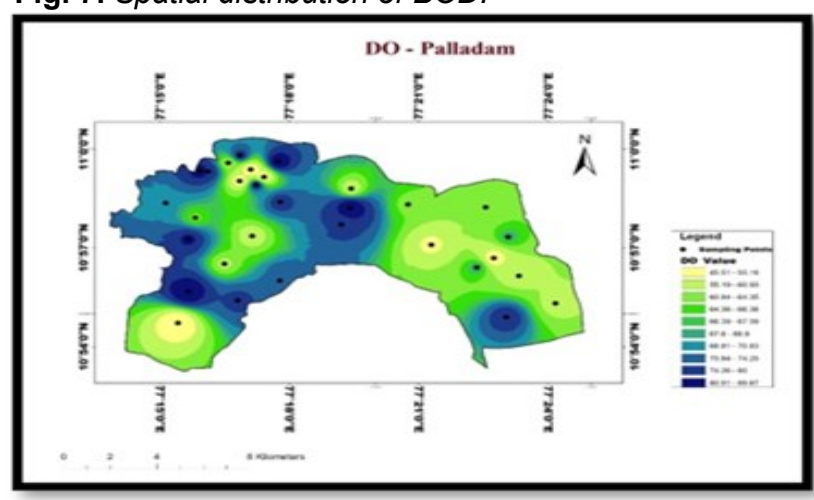

Fig. 9. Spatial distribution of DO.

trations were ranged from $0 \mathrm{mg} / \mathrm{L}$ to $1.5 \mathrm{mg} / \mathrm{L}$ with an average value of $0.694 \mathrm{mg} / \mathrm{L}$. BOD in the water samples of the study area varied from 1.1 to 2.6 with an average value of $1.95 \mathrm{mg} / \mathrm{L}$. The spatial analysis of $\mathrm{F}^{-}$ (Fig. 6) and BOD (Fig. 7) in the water samples indicated 


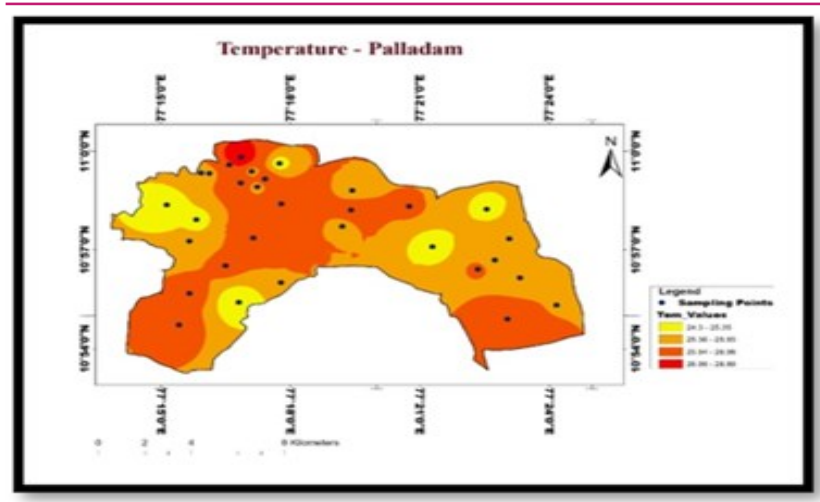

Fig. 10. Spatial distribution of temperature.

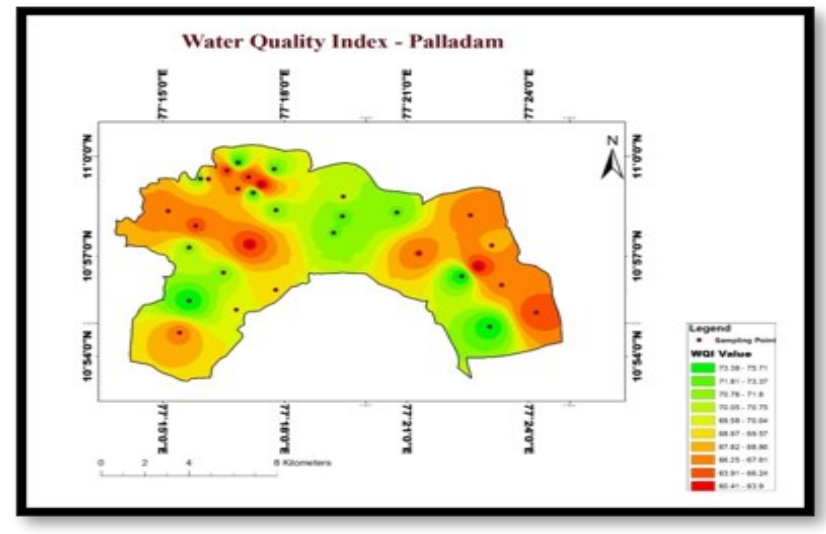

Fig. 12. Spatial distribution of WQI.

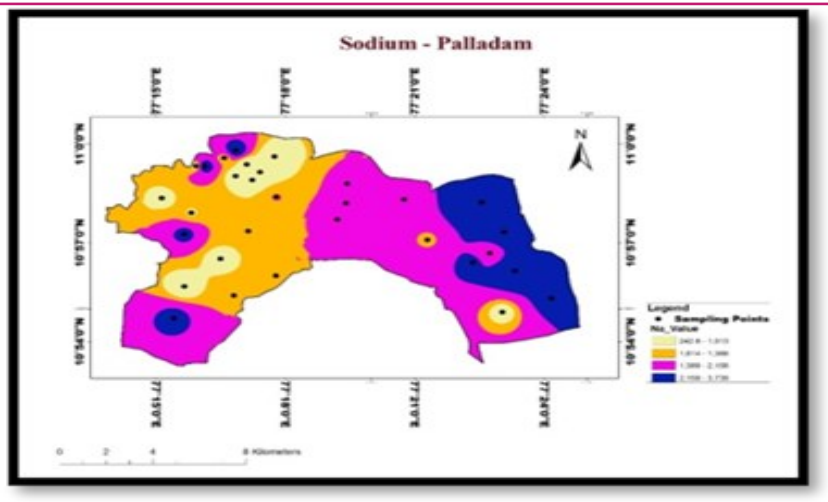

Fig. 11. Spatial distribution of sodium.

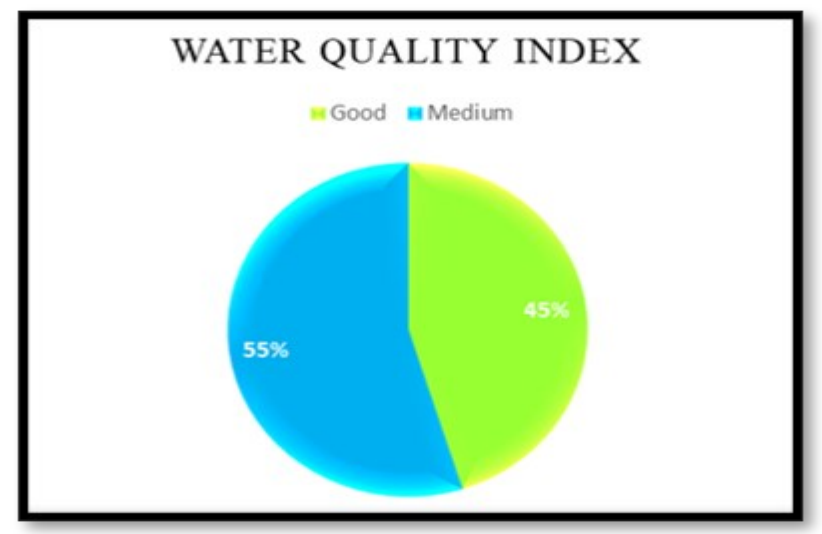

Fig.13. WQI variation in Palladam taluk.

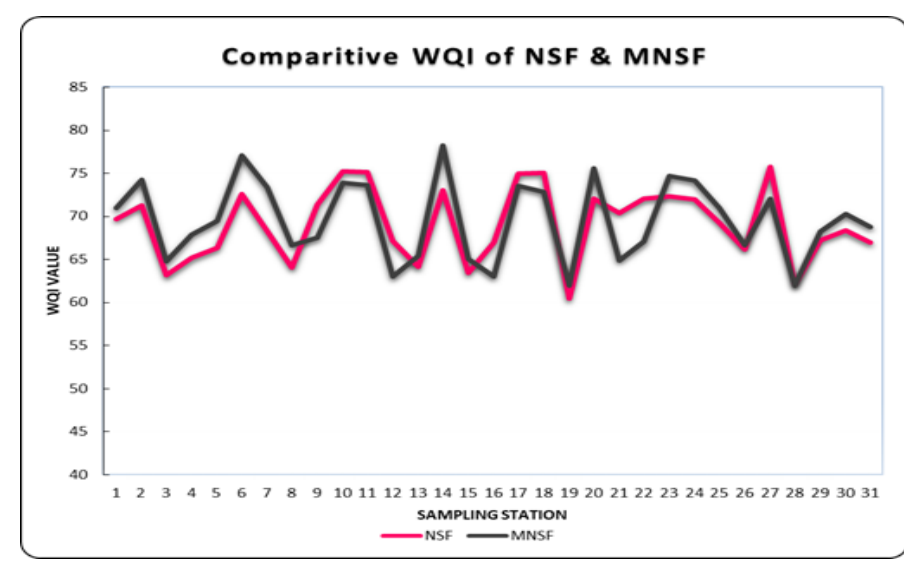

Fig. 14. Comparison of the WQI values of NSF and MNSF.

that all samples were within acceptable limits. The electric conductivity of the water is directly proportional to the concentration of dissolved matter in the water (Şener et al., 2017). EC value of the water samples ranged from $0.06 \mathrm{mS}$ to $5.56 \mathrm{mS}$ (Fig. 8). The results showed that all the water samples in the study area are within the desirable limit $300 \mathrm{mS}$. Dissolved oxygen is a vital parameter reflecting the quality of water. The values of WQI depending upon the value of DO in water. $\mathrm{DO}$ in the water samples of the study area were ranged from $45.5 \%$ to $89.7 \%$ with an average value of $67.5 \%$. The spatial analysis of DO (Fig. 9) reveals that the sampling point (S15) have the lowest DO value (48.9) and S14 have the highest DO value (78.9). Tempera- ture varied from $24.3^{\circ} \mathrm{C}$ to $28.9^{\circ} \mathrm{C}$ (average value $25.9^{\circ}$ C). The spatial analysis of temperature (Fig. 10) of the samples was within the permissible limit recommended by WHO (2017) and BIS (2012). Na is a primary chemical in human body fluids and is not considered harmful at normal absorption levels from food sources and drinking water combined. The higher level of sodium affects the man via seizures and hypertension (Gnanachandrasamy et al., 2020). The amount of $\mathrm{Na}^{+}$ ion in Palladam Taluk ranged from $240 \mathrm{mg} / \mathrm{L}$ to 3740 $\mathrm{mg} / \mathrm{L}$ (avg. $1603 \mathrm{mg} / \mathrm{L}$ ). The spatial analysis of $\mathrm{Na}^{+}$ (Fig.11) indicated that all the water samples were above the permissible limit of WHO, 2017. According to the Table 1, it is clear that the concentrations of TP, 
Table 2. Water quality level of Palladam Taluk.

\begin{tabular}{lll}
\hline Water Quality & Quality of the water & No. of samples \\
\hline $90-100$ & Excellent & 0 \\
$70-89$ & Good & 14 \\
$50-69$ & Medium & 17 \\
$25-49$ & Bad & 0 \\
$0-24$ & Very bad & 0 \\
\hline
\end{tabular}

TN, FC and TUR were within the desirable limits (World Health Organization, 2017). Faecal Coliform and temperature values of surface water were higher than groundwater. Surface water seemed to be slightly alkaline in nature when compared with groundwater.

\section{Water Quality Index (WQI)}

The WQI indicates the quality of water in relation to an index that reflects the overall status of water quality for consumption. The spatial distribution of the WQI of the current study area is depicted in Fig.12. WQI computed by incorporating the nine WQI parameters viz. temperature, $\mathrm{pH}, \mathrm{DO}, \mathrm{BOD}$, TUR, TDS, FC, TP and TN into the GIS provided the quality of water, whether suitable or unsuitable for consumption. The GIS-based WQI map analysis (Fig.13) indicated that $55 \%$ of the study area showed a medium water quality index and the remaining area showed good quality water given in Table 2. Results indicated that water available from the study area $(55 \%)$ is inappropriate for direct utilization and needs prior treatment. Treated water from dyeing and textile industries when discharged into water bodies it increases the temperature, alters $\mathrm{pH}$, hence it disrupts the natural balance of aquatic life. Previously no study has been done on GIS based water quality index for the Palladam Taluk.

\section{Water quality parameters based on the Modified NSF-Water Quality Index (MNSF-WQI)}

The modified water quality index was derived by using seven water quality parameters instead of using nine parameters. The obtained results from NSF-WQI and MNSF-WQI are comparable. Fig.14 picturized the close relationship between the NSF and the Modified NSF formula.

\section{Conclusion}

In the present study, the assessment of the water quality of Palladam Taluk, Tiruppur district using MNSF-WQI and GIS mapping helped to understand and visualize the current status of ground and surface water in the study area. The assessment results showed that all the physicochemical parameters viz tem, $\mathrm{pH}, \mathrm{DO}, \mathrm{EC}$, BOD, TUB, FC, TP, TN and $\mathrm{F}^{-}$were within the desirable limit except $\mathrm{Cl}^{-}, \mathrm{Na}$ ion, $\mathrm{TH}$ and TDS as per standard guidelines. The spatial distribution map showed that $45 \%$ of the study area fell under good water quality and $55 \%$ area medium water quality classes. Several dyeing and textile industries in the study area were responsible for the deterioration of the water to medium quality of water. The GIS based WQI map can be used to plan the future development programs for ground and surface water quality management of the study area of Palladam Taluk.

\section{Conflict of interest}

The authors declare that they have no conflict of interest.

\section{REFERENCES}

1. Ameen, H. A. (2019). Spring water quality assessment using water quality index in villages of Barwari Bala, Duhok, Kurdistan Region, Iraq. Appl. Water Sci, 9, 1-12.

2. American Public Health Association (2017). Standard methods for examination of water and waste water.23th Ed.Washington DC, USA.

3. Arumugam, K. \& Elangovan, K. R. K. A. (2016). Groundwater Quality Assessment for Drinking Purpose and Identification of Sources Controlling Groundwater Chemistry in Parts of Tirupur District, Tamil Nadu, India. Int. J. Curr. Res. Sci. Eng. Technol, 12, 6-12.

4. Boateng, T. K., Opoku, F. Acquaah, S. O. \& Akoto, O. (2016). Groundwater quality assessment using statistical approach and water quality index in Ejisu-Juaben Municipality, Ghana. Environ. Earth Sci, 75(6). https:// doi.org/10.1007/s12665-015-5105-0.

5. Bureau of Indian Standards (2012) Indian Standard Drinking Water Specification 10500. Bureau of Indian Standards (BIS).

6. Chandra, S., Singh, P.K., Tiwari, A.K., Panigrahy, B. \& Kumar, A. (2015). Evaluation of hydrogeological factor and their relationship with seasonal water table fluctuation in Dhanbad district, Jharkhand, India. ISH J. Hydraul. Eng, 21,193-206.

7. Chen, S. K., Jang, C. S. \& Chou, C. Y. (2019). Assessment of spatiotemporal variations in river water quality for sustainable environmental and recreational management in the highly urbanized Danshui River basin. Environ. Monit. Assess, 191, 100.

8. Cristable, R. M., Nurdin, E. \& Wardhana, W. (2020). Water quality analysis of Saluran Tarum Barat, West Java, based on National Sanitation Foundation-Water Quality Index (NSF-WQI). IOP Conf. Ser. Earth Environ. Sci, 481 (1). https://doi.org/10.1088/1755-1315/481/1/012068. 
9. Deng, W. \& Wang, G. A. (2017). Novel water quality data analysis framework based on time-series data mining. $J$. Environ. Manag, 196(1), 365-375.

10. Deshmuk. Keshav. \& Sainath. (2016). Assessment of the impact of municipal solid waste on groundwater quality near the Sangamner city using GIS approach. Water. Resour. Manag, 30(7), 2425-2443.

11. Dixon, W. \& Chiswell, B. (1996). Review of aquatic monitoring program design, Water. Res, 30(9), 1935-1948.

12. Ewaid, S. H., Abed, S. A. \& Kadhum, S. A. (2018). Predicting the Tigris River water quality within Baghdad, Iraq by using water quality index and regression analysis. Environ. Technol. and Inno, 11, 390-398. https:// doi.org/10.1016/j.eti.2018.06.013

13. Ganesh Babu, O. \& Sashikkumar, M.C. (2013). Application of GIS for ground water quality mapping of Tiruppur block, Tamil Nadu. Int.J. of Remote Sensing \& Geoscience, 2(5), 18-25.

14. Gnanachandrasamy, G., Dushiyanthan, C., Jeyavel Rajakumar, T. \& Zhou, Y. (2020). Assessment of hydrogeochemical characteristics of groundwater in the lower Vellar river basin: using Geographical Information System (GIS) and Water Quality Index (WQI). Environ. Dev. Sustain. vol. 22.

15. Ji, X., Dahlgren, R. A. \& Zhang, M. (2016). Comparison of seven water quality assessment methods for the characterization and management of highly impaired river systems, Environ. Monit. Assess, 188 (15) doi: 10.1007/ s10661-015-5016-2. Epub 2015 Dec 7.

16. Mitra, B.K., Sasaki, C. \& Keijirou, E. (2006). Spatial and temporal variation of ground water quality in sand dune groundwater sample of Aomori prefecture in Japan. In: 2006 ASAE annual meeting, ASABE, 1.

17. Mladenović-Ranisavljević, I. I., Takić, L. \& Nikolić, D. (2018). Water quality assessment based on combined multi-criteria decision-making method with index method. Water Resour. Manag, 32, 2261-2276.

18. Mohammad, M.A. \& Saminu M, Y. (2012). Water quality and phytoplankton of Salanta River, Kano, Nigeria. J. Biol. Sci. Biocons, 4, 65-73.

19. Rakotondrabe, F., José Paulo Soares de Azevedo., Marco Aurélio dos Santos \& Rafaela dos. Santos Facchetti Vinhaes Assumpção. (2018). Water quality assessment in the Bétaré-Oya gold mining area (East-Cameroon): multivariate statistical analysis approach, Sci. Total Environ, 610 611, 831-844.

20. Ramakrishna., Nagaraju, D. Mohammad Suban Lone., Siddalingamurthy, S. \& Sumithra, S. (2013). Ground water prospectus studies of Tattekere watershed, Mysore district, Karnataka, India using remote sensing and GIS. Int. J. Remote Sens. Geosci, 3(1), 6-10.

21. Ramakrishnaiah, C.R., Sadashivaiah, C. \& Ranganna, G. (2009). Assess- ment of water quality index for the groundwater in Tumkur Taluk, Karnataka State, India. $J$ Chem, 6, 523-530.

22. Rawat, K. S. \& Singh, S. K. (2018). Water quality indices and GIS-based evaluation of a decadal groundwater quality. Geol. Ecol. Landsc, 2(4), 240-255. https://doi.org/10.1 080/24749508.2018.1452462

23. Saleem, M. Hussain, A. \& Mahmood, G. (2016). Analysis of groundwater quality using water quality index: A case study of greater Noida (Region), Uttar Pradesh (U.P), India. Cogent Engineering, 3(1). https://doi.org/10.10 80/23311916.2016.1237927.

24. Şener, Ş., Şener, E. \& Davraz, A. (2017). Evaluation of water quality using water quality index (WQI) method and GIS in Aksu River (SW-Turkey). Sci. Total Environ. 584585, 131-144.

25. Tiwari, A. K., Singh, A. K. \& Mahato, M. K. (2018). Assessment of groundwater quality of Pratapgarh district in India for suitability of drinking purpose using water quality index (WQI) and GIS technique. Sus. Water. Resour. Manag, 4(3), 601-616. https://doi.org/10.1007/s40899017-0144-1

26. Vasanthavigar, M., Srinivasamoorthy, K., Vijayaragavan, K., Rajiv Ganthi, R. Chidambaram, S., Anandhan, P., Manivannan, R. \& Vasudevan, S. (2010). Application of water quality index for groundwater quality assessment: Thirumanimuttar sub-basin, Tamilnadu, India. Environ. Monit. Assess, 171(1-4), 595-609. https://doi.org/10.1 007/s10661-009-1302-1

27. Wada, Y. Flörke., M. Hanasaki, N., Eisner, S., Fischer, G., Tramberend, S. Satoh, Y., van Vliet, M. T. H. Yillia, P., Ringler, C., Burek, P. \& Wiberg, D. (2016). Modeling global water use for the 21st century the Water Futures and Solutions (WFaS) initiative and its approaches, Geo sci. Model Dev, 9, 175-222. https://doi.org/10.5194/gmd-9175-2016.

28. Wang, Y., Xiang, C., Zhao, P., Mao, G. \& Du, H. (2016). A bibliometric analysis for the research on river water quality assessment and simulation during 2000-2014. Scientometrics, 108(3), 1333-1346.

29. World Health Organization (2017) Guidelines for drinking water quality first addendum to $3^{\text {rd }} \mathrm{Ed}(1)$. World Health Organization (WHO). Recommendations Geneva.

30. Yadav, K. K., Gupta, N., Kumar, V., Sharma, S. \& Arya, S. (2015). Water quality assessment of Pahuj River using water quality index at Unnao Balaji , M . P ., India. Int. J. Sci. Basic and App. Research, 19(1), 241-250.

31. Zotou, I., Tsihrintzis, V. A. \& Gikas, G. D. (2020). Water quality evaluation of a lacustrine water body in the Mediterranean based on different water quality index (WQI) methodologies. J. Environ. Sci. Health A Tox. Hazard Subst. Environ. Eng., 55(5), 537-548. https://doi.org/10.10 80/10 93 4529.2019.1710956. 